\title{
Round Pneumonia in a 50-Year-Old Man
}

\author{
Burke A Cunha MD, Arthur Gran MD, and Jaime Simon MD
}

\section{Introduction}

Round pneumonia is a term referring to round or oval densities on chest $\mathrm{x}$-ray. Round pneumonias have rarely been reported. First recognized in children, round pneumonias were due to Streptococcus pneumoniae or Haemophilus influenzae. Round pneumonias are probably frequently undiagnosed in the adult population, The appearance of such a pneumonia on chest x-ray may be round or oval, the borders may be smooth or lobulated. Round pneumonias may be accompanied by air bronchograms, and are usually located in the lower lobes of the lung. Most round pneumonias are small and solitary, but others are multiple and may be larger. Cavitation is not a usual feature of round pneumonias. Infiltrates may contain calcifications or be spiculated. There are many potential causes of round pneumonia, some of which are infectious and others are mimics of pneumonia. In adults the usual diagnostic challenge of a round pneumonia is to differentiate bacterial pneumonia from bronchogenic carcinoma. ${ }^{1,2}$

\section{Case Summary}

A 50-year-old male presented to his primary care physician with cough, fever, malaise, myalgias, and shortness of breath that began 1 week before admission. He reported no recent travel, sick contacts, animal contacts, or environmental exposures. His past medical history included hypertension and schizophrenia, well controlled on medication. His physician performed a chest $\mathrm{x}$-ray in the office, which was abnormal, and the patient was referred to our institution for diagnostic work-up.

The authors are affiliated with the Infectious Disease Division, Winthrop University Hospital, Mineola, New York, and with the School of Medicine, State University of New York, Stony Brook, New York.

The authors have disclosed no conflicts of interest.

Correspondence: Burke A Cunha MD, Infectious Disease Division, Winthrop University Hospital, 222 Station Plaza North, Suite 432, Mineola NY 11501.

DOI: $10.4187 /$ respcare.02219
Vital signs revealed a temperature of $37.9^{\circ} \mathrm{C}$, a pulse 108 beats/min, a blood pressure of $137 / 71 \mathrm{~mm} / \mathrm{Hg}$, and a breathing frequency of 18 breaths/min. His physical examination was unremarkable except for tachycardia and right upper lobe rales.

Complete blood count revealed a white blood cell count of $14.4 \times 10^{3} / \mathrm{mL}$, a hemoglobin of $9.9 \mathrm{~g} / \mathrm{dL}$, a hematocrit of $28.9 \%$, and a platelet count of $406 \times 10^{3} \%$ $\mathrm{mL}$. The erythrocyte sedimentation rate was $104 \mathrm{~mm} / \mathrm{h}$. His serum ferritin level was $407 \mathrm{ng} / \mathrm{mL}$ (normal 14$235 \mathrm{ng} / \mathrm{mL}$ ), alanine aminotransferase was $22 \mathrm{IU} / \mathrm{L}$ (normal 4-36 IU/L), aspartate aminotransferase 22 IU/L (normal 13-39 IU/L), and alkaline phosphatase $55 \mathrm{IU} / \mathrm{L}$ (normal 25-100 IU/L). Procalcitonin level was $0.11 \mathrm{mg} / \mathrm{mL}$ (normal $0-0.5 \mathrm{mg} / \mathrm{mL}$ ). Figure 1 shows his admission chest $\mathrm{x}$-ray. Urine legionella antigen, legionella species titer, and Mycoplasma pneumoniae and Chlamydia pneumoniae immunoglobulin-M (IgM) and $\mathrm{IgG}$ titers were negative. Cold and febrile agglutinins were negative, Anti-smooth muscle antibody titers were negative. $\mathrm{Q}$ fever phase I and II antigens were negative. Blood, urine, and sputum cultures were negative. He was treated empirically for 6 weeks with doxycycline, which has activity against all of the infectious causes of round pneumonias. A specific etiology was not identified. Repeat chest x-ray taken 8 weeks later demonstrated near resolution of the round pneumonia (Fig. 2).

\section{Discussion}

Patients with round pneumonias due to infection often present with antecedent symptoms of fever and cough for 1-2 weeks. In others, round densities are often an incidental finding on chest $\mathrm{x}$-rays. Noninfectious/non-neoplastic causes of round pneumonias include atelectasis and congenital bronchopulmonary sequestration, which usually occurs at the lung bases, more commonly on the left. ${ }^{3,4}$ If the history suggests a bacterial etiology, the work-up should look for $S$. pneumoniae, H. influenzae, and, particularly in adults, Q fever and Legionella micdadei. S. pneumoniae and $H$. influenzae pneumonias are acquired by inhalation and on chest x-ray typically begin at the pleura, cause pleural chest pain and pleural effusion, and later extend along the segment within the major fissures of the lungs. 


\section{Round Pneumonia in a 50-Year-Old Man}

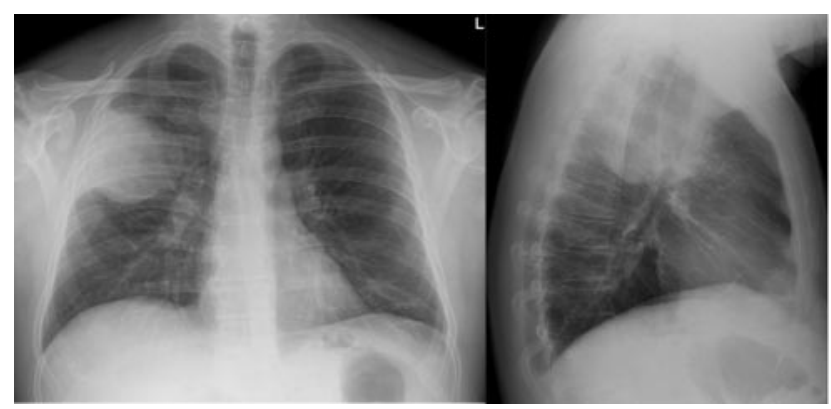

Fig. 1. Admission chest $\mathrm{x}$-rays in a 50-year-old man with round pneumonia.

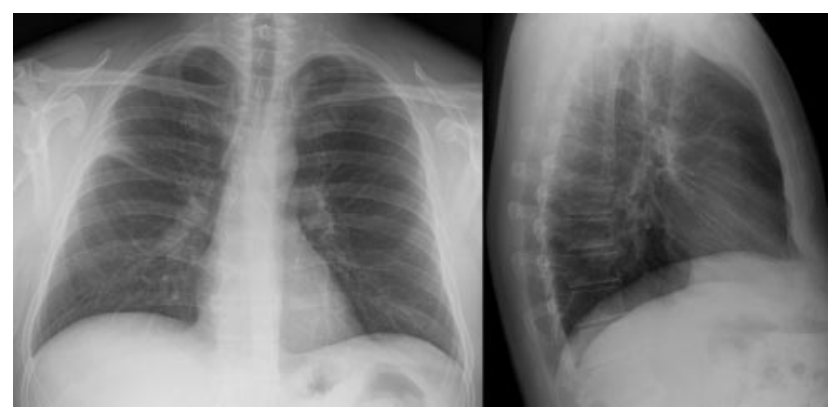

Fig. 2. Chest $x$-rays 8 weeks later show near complete resolution of round pneumonia.

Table. Differential Diagnosis of Round Pneumonia in Adults

\begin{tabular}{l}
\hline \hline Infectious Causes \\
Q fever \\
Legionella micdadei \\
Streptococcus pneumoniae \\
Haemophilus influenzae \\
Rickettsia typhi \\
Non-Infectious Causes \\
Bronchogenic carcinoma \\
Round atelectasis \\
Bronchopulmonary sequestration \\
Bronchiolitis obliterans organizing pneumonia \\
Wegener granulomatosis \\
Septic pulmonary emboli \\
Rheumatoid nodules
\end{tabular}

Approximately $75 \%$ of round pneumonias have no proven etiology (Table). ${ }^{5-7} \mathrm{Q}$ fever round pneumonias occur more commonly in $\mathrm{Q}$ fever epidemic areas, and also occur in $14 \%$ of sporadic cases. Q fever round pneumonias are $5-10 \mathrm{~cm}$ in diameter, and usually located in the lower lobes. While all the diagnostic tests for round pneumonia pathogens were negative, the diagnostic tests were focused on $\mathrm{Q}$ fever and Legionella micdadei. Q fever is a zoonotic infection, usually transmitted to humans from parturient cats or sheep. Acute Q fever presents as a zoonotic atypical pneumonia, relative bradycardia, and often spleno- megaly. Non-specific laboratory tests associated with Q fever pneumonia include a highly elevated erythrocyte sedimentation rate, thrombocytosis, mildly elevated transaminases, elevated cold agglutins, or elevated antismooth-muscle-antibody titers.

Legionella micdadei pneumonia is associated with relative bradycardia, but with none of the other extrapulmonary findings of $\mathrm{Q}$ fever pneumonia (vide supra). Initial infiltrates on the chest $\mathrm{x}$-ray may become rounded during resolution of pneumonia, ${ }^{8,9}$ so the radiologic appearance of a round pneumonia depends largely on when the chest $\mathrm{x}$-ray is taken relative to the time the patient presents. Air bronchograms are common with bronchogenic carcinomas but do not help to differentiate infectious from non-infectious round pneumonias. ${ }^{10}$ The round appearance on chest $\mathrm{x}$-ray is thought to occur from an infectious process that spreads from small peripheral alveoli centrifugally through interalveolar channels via the pores of Kohn and the channels of Lambert. This explains the non-segmental distribution and shape of round pneumonias. ${ }^{1,3}$ Because specific etiologic diagnosis of round pneumonia is not always possible, the best clinical approach is to differentiate infectious from malignant etiology. ${ }^{1,9}$ For this purpose, serial chest $\mathrm{x}$-rays are most helpful. Inflammatory/infectious round infiltrates resolve over time. In contrast, neoplastic infiltrates do not resolve with antibiotic therapy or over time. If a round pneumonia resolves with antimicrobial therapy, the round pneumonia was likely due to an infectious disease. ${ }^{1,3,8}$ Suspicion that a round pneumonia may be malignant can be settled with chest computed tomography and biopsy.

\section{Teaching Points}

- Round pneumonias are more common in children than adults.

- Round pneumonias appear as single or multiple nodular densities, and occur predominantly in the lower lobes.

- Upper lobe round or oval x-ray opacities are more likely to suggest a malignant rather than infectious etiology.

- Common causes of round pneumonias in children are community-acquired $S$. pneumoniae and $H$. influenzae.

- Common causes of round pneumonias in adults are $\mathrm{Q}$ fever and Legionella micdadei, so in adults with round pneumonias, Coxiella burnetii and Legionella species titers should be sent.

- Serial chest x-rays are helpful in differentiating malignant from benign causes of round pneumonias.

- Persistence and progression of a round pneumonia on chest $\mathrm{X}$-ray favors a malignant process, whereas decreased 


\section{Round Pneumonia in a 50-Year-Old Man}

size or resolution of a round pneumonia on chest $\mathrm{x}$-ray favors an infectious etiology.

- The appearance of a round pneumonia on chest x-ray is largely dependent on whether the chest $\mathrm{x}$-ray is taken early or late in the course of the disease process.

- Most presentations of infectious round pneumonias are preceded by 1-2 weeks of cough and fever, whereas those with a malignant etiology are usually asymptomatic.

\section{REFERENCES}

1. Hershey C, Panaro V. Round pneumonia in adults. Arch Intern Med 1988;148(5):1155-1156.

2. Wagner A, Szabunio M, Hazlett K, Wagner S. Radiologic Manifestations of round pneumonia in adults. AJR Am J Roentgenol 1998; 170(3):723-725.
3. McLennan MK. Radiology rounds: round pneumonia. Can Fam Physician 1998;44:751, 757-759.

4. Miyake H, Kaku A, Okino Y, Hori Y, Nakano F, Takuma M, et al. [Clinical manifestations and chest radiographic and CT findings of round pneumonia in adults]. Nihon Igaku Hoshasen Gakkai Zasshi 1999;59(9):448-451. Article in Japanese.

5. Anton E. A frequent error in etiology of round pneumonia. Chest 2004;125(4):1592-1593.

6. Fretzayas A, Moustaki M, Alexopoulou E, Liapi O, Nicolaidou P, Priftis KN. Observations in febrile children with round air space opacities. Pediatr Int 2010;52(3):444-446.

7. Kara PH, Demircan A, Akinci E, Bildik F, Aygencel G, Ozsarac M. Focal mass-like opacity on chest radiography: round pneumonia. Visual diagnosis in emergency medicine. J Emerg Med 2010;39(1): e89-e90. DOI: 10.1016/j.jemermed.2007.11.106.

8. Wagner AL. Round pneumonia and focal organizing pneumonia are different entities. Am J Radiol 1999;172(2):549-550.

9. Cunha BA, editor. Pneumonia essentials, 3rd edition. Sudbury, MA: Jones \& Bartlett; 2010.

10. Reed JC. Chest radiology: plain film patterns and differential diagnoses, 3rd edition. St Louis: Mosby; 1991:167-338. 